\title{
Comprehensive Molecular Cytogenetic Characterization of Cervical Cancer Cell Lines
}

\author{
Charles P. Harris,' Xin Yan Lu,' Gopeshwar Narayan, ${ }^{2}$ Bhuvanesh Singh, ${ }^{3}$ Vundavalli V. V. S. Murty, ${ }^{2}$ \\ and Pulivarthi H. Rao ${ }^{1 *}$ \\ 'Laboratory of Molecular Cytogenetics, Texas Children's Cancer Center, Baylor College of Medicine, Houston, Texas \\ 2Department of Pathology and Institute of Cancer Genetics, College of Physicians \& Surgeons of Columbia University, New York, \\ New York \\ ${ }^{3}$ Laboratory of Epithelial Cancer Biology, Memorial Sloan-Kettering Cancer Center, New York, New York
}

\begin{abstract}
We applied a combination of molecular cytogenetic methods, including comparative genomic hybridization (CGH), spectral karyotyping (SKY), and fluorescence in situ hybridization (FISH), to characterize the genetic aberrations in eight widely used cervical cancer (CC) cell lines. CGH identified the most frequent chromosomal losses including 2q, 3p, 4q, 6q, 8p, 9p, 10p, $13 q$, and 18q; gains including 3q, 5p, 5q, 8q, 9q, IIq, I4q, I6q, 17q, and 20q; and high-level chromosomal amplification at 3q2।, $7 p I I, 8 q 23-q 24,10 q 21,1|q| 3,16 q 23-q 24,20 q 11.2$, and 20q13. Several recurrent structural chromosomal rearrangements, including $\operatorname{der}(5) \mathrm{t}(5 ; 8)(\mathrm{pl} 3 ; \mathrm{q} 23)$ and $\mathrm{i}(5)(\mathrm{pl0})$; deletions affecting chromosome bands $5 \mathrm{pl} \mathrm{I}, 5 \mathrm{qI}$, and I Iq23; and breakpoint

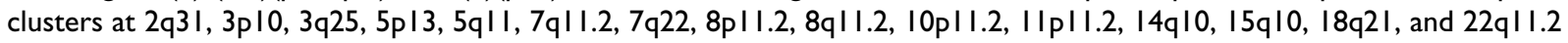
were identified by SKY. We detected integration of HPVI 6 sequences by FISH on the derivative chromosomes involving bands I8pIO and I8pII in cell line C-4I, 2pI6, 5q2I, 5q23, 6q, 8q24, I0, IIpII, I5q, and I8pII in Ca Ski, and normal chromosome 17 at $17 \mathrm{p} / 3$ in ME-180. FISH analysis was also used further to determine the copy number changes of PIKA3CA and MYC. This comprehensive cytogenetic characterization of eight CC cell lines enhances their utility in experimental studies aimed at gene discovery and functional analysis. () 2003 Wiley-Liss, Inc.
\end{abstract}

\section{INTRODUCTION}

Cervical cancer (CC) is the second most common gynecologic malignancy in the world in both incidence and mortality. Infection with human papilloma virus (HPV) is considered an initiating factor in CC carcinogenesis (Brisson et al., 1994). Although $95 \%$ of the patients with precancerous lesions harbor HPV, only a small fraction of the cases eventually progress to invasive cancer (zur Hausen, 2000). Therefore, HPV infection alone was considered insufficient for malignant conversion, suggesting a role of other genetic changes in the development of CC. Identification of such genetic alterations is critical for our understanding of the molecular basis of CG development. Thus, cell lines provide an excellent and continuous source of tumor material for such a genetic characterization.

Conventional cytogenetic analysis has identified several recurrent structural chromosomal changes involving chromosomes $1,3,5,17$, and the $\mathrm{X}$ chromosome in CG (Atkin, 1997). A precise cytogenetic characterization in CC was not feasible because of the difficulty in identifying complex chromosome changes in primary tumors. Recently, however, several molecular cytogenetic techniques, such as fluorescence in situ hybridization (FISH), comparative genomic hybridization $(\mathrm{CGH})$, and spectral karyotyping (SKY)/multicolor-FISH (m-FISH), have been used to illustrate the precise genetic aberrations in tumor genomes (Kallioniemi et al., 1992; Schröck et al., 1996; Speicher et al., 1996; Singh et al., 2001; Rao et al., 2002). Several cell lines derived from patients with CC are available that provide a renewable source of material for genetic analysis and that have been used in various studies. Therefore, complete cytogenetic characterization of CC lines will provide useful genetic information for multiple studies.

Here, we characterized eight widely used $\mathrm{CC}$ cell lines by G-banding, CGH, SKY, and FISH, and we present their comprehensive molecular cytogenetic profiling. These cell lines have previously not been subjected to detailed cytogenetic characterization. We identified several chromosomal regions that may be important in tumor de-

\footnotetext{
Supported by: The Elain B. Lesser Foundation; The Herbert Irving Cancer Center, Columbia University, New York.

*Correspondence to: Dr. Pulivarthi H. Rao, Laboratory of Molecular Cytogenetics, Texas Children’s Cancer Center, Baylor College of Medicine, 6621 Fannin Street, MC 3-3320, Houston TX 77030. E-mail: phrao@txccc.org

Received 13 May 2002; Accepted 20 July 2002

DOI 10.1002/gcc.10158
} 
velopment. Losses of $2 q$ and gains of $3 q, 5 p$, and $8 q$ were significant. Notably, the combined approach of CGH, SKY, and FISH analysis defined the origin of $2 q$ loss and gain of 3q, 5p, and 8q. In addition, we identified several amplified chromosomal regions: 3q21, 7p11, 8q23-q24, 10q21, 11q13, 16q23-q24, 20q11.2, and 20q13.1. Through FISH, we have also shown the integration of HPV16 sequences in three of the eight cell lines. This comprehensive characterization of these cell lines augments their utility in investigations targeted at gene discovery and functional analysis in CC.

\section{MATERIALS AND METHODS}

\section{Cell Lines}

The cell lines (Ca Ski, C-33A, C-4I, HT-3, ME180, MS751, SiHa, and SW756) were obtained from the American Type Culture Collection (ATCC, Manassas, VA), and were grown according to the supplier's recommendations. Chromosome preparations and G-banded karyotypes were made by standard protocols. Clonal chromosomal abnormalities identified by G-banding were described according to An International System for Human Cytogenetic Nomenclature (ISCN, 1995). Clonality was described by detection of two cells with the same structural abnormality or chromosomal gain and loss of the same chromosome in three cells. The metaphase spreads were aged at room temperature for 1 week for SKY. The consensus karyotype was generated for each cell line on the basis of G-banding and SKY analysis.

\section{CGH}

High molecular weight DNA was isolated from cell lines and normal placenta by standard methods and subjected to $\mathrm{CGH}$ according to a previously published method, with some modifications (Kallioniemi et al., 1992). The metaphase preparations were captured and processed by use of the Quantitative Image Processing System (Applied Imaging, Santa Clara, CA).

\section{SKY}

The cocktail of human chromosome paints was obtained from Applied Spectral Imaging (ASI, Carlsbad, CA). Hybridization and detection were carried out according to the manufacturer's protocol, with slight modifications. Chromosomes were counterstained with 4',6-diamidino-2-phenylindole (DAPI). For each case, at least five metaphase cells were analyzed by SKY. Images were acquired with a SD200 Spectra cube (ASI) mounted on a Zeiss
Axioplan II microscope (Zeiss, Jena, Germany) by use of a custom-designed optical filter (SKY-1; Chroma Technology, Brattleboro, VT) and analyzed by use of SKY View 1.2 software (ASI).

The breakpoints on the SKY-painted chromosomes were determined by comparison of corresponding inverted-DAPI banding of the same chromosome and by comparison with the G-banded karyotype for each cell line. By this method, we were able to define the breakpoints on add and der chromosomes, but were unable to assign the precise breakpoints of chromosomal segments from partner chromosomes that generated the add or der chromosomes. A breakpoint was considered to be recurrent if it was identified in two or more cases (Rao et al., 1998). A breakpoint cluster was defined as the occurrence of four or more breakpoints in the same chromosomal band.

\section{FISH}

FISH was performed to identify the HPV16 integration sites and copy number changes of $M Y C$ (8q24) and PIKA3CA (3q26.3) in eight CC cell lines. The plasmid containing HPV16 sequences and the BAC clone (386M7) containing PIKA3CA was labeled by nick translation with Spectrum Red/ Spectrum Green (Vysis, Downers Grove, IL). The digoxigenin-labeled $M Y C$ probe was obtained from Ventana (Tucson, AZ). Hybridization and detection were performed according to the manufacturer's protocols.

\section{RESULTS}

\section{DNA Copy Number Changes Identified by CGH}

The most frequent chromosomal losses included 1p (38\%), 2q (100\%), 3p (62\%), 4q (88\%), 6q (63\%), 8p (75\%), 9p (38\%), 10p (63\%), 10q (38\%), 11p (38\%), 11q (38\%), 13q (75\%), and 18q (88\%); and gains included $1 \mathrm{p}(38 \%), 3 \mathrm{q}(50 \%), 5 \mathrm{p}(63 \%), 5 \mathrm{q}$ (38\%), 7p (63\%), 7q (63\%), 9q (88\%), 11q (50\%), $14 q(50 \%), 15 q(38 \%), 16 q(50 \%), 17 q(63 \%), 19 q$ (50\%), 20p (25\%), 20q (88\%), and Xq (38\%) (Fig. $1 \mathrm{~A})$.

Figure I. A: Ideograms showing DNA copy number changes identified by $\mathrm{CGH}$ in the cell lines. Thin vertical lines on either side of the ideogram indicate losses (left) and gains (right) of the chromosomal region. High-level amplifications are shown as thick lines (right). B: Ideograms showing all of the breakpoints noted in the cell lines identified by SKY (inverted-DAPI) in combination with G-banding ( $\star$ represents translocation breakpoint, - represents deletion breakpoint, I represents duplication breakpoint). The number of breakpoints in each chromosome that were identified by SKY/G-banding, but could not precisely be assigned to a chromosomal band, are noted in the box on top of the chromosome. 
A

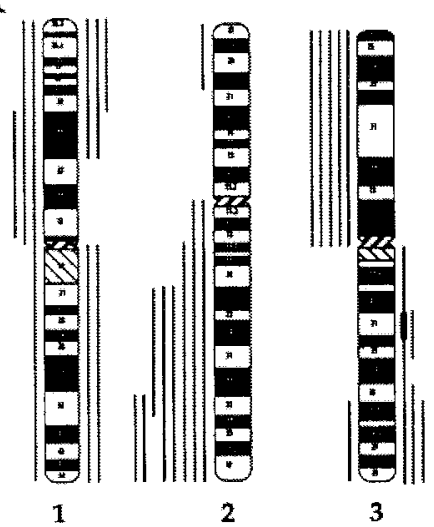

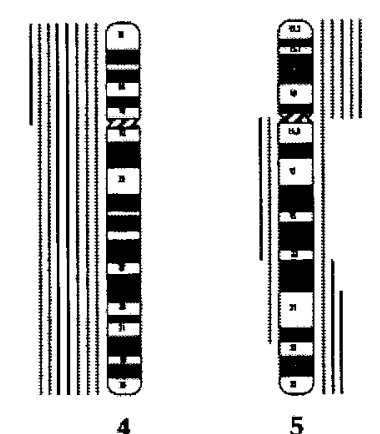

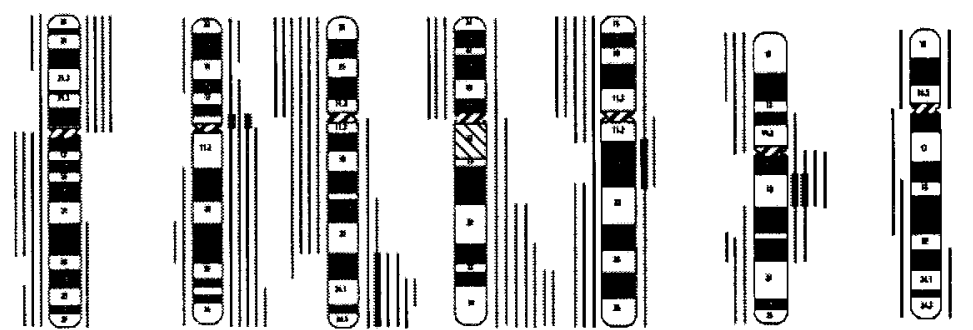

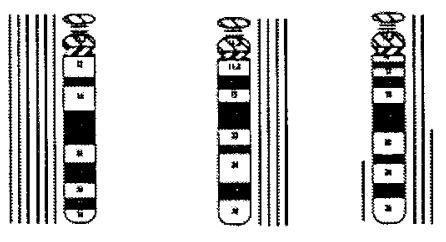

$1314 \quad 14$

||l|

19

20

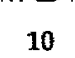

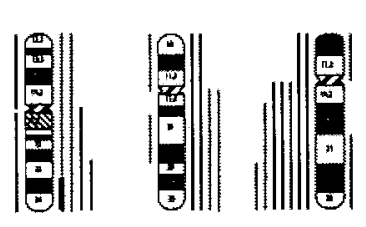

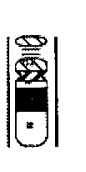

21

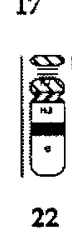

B

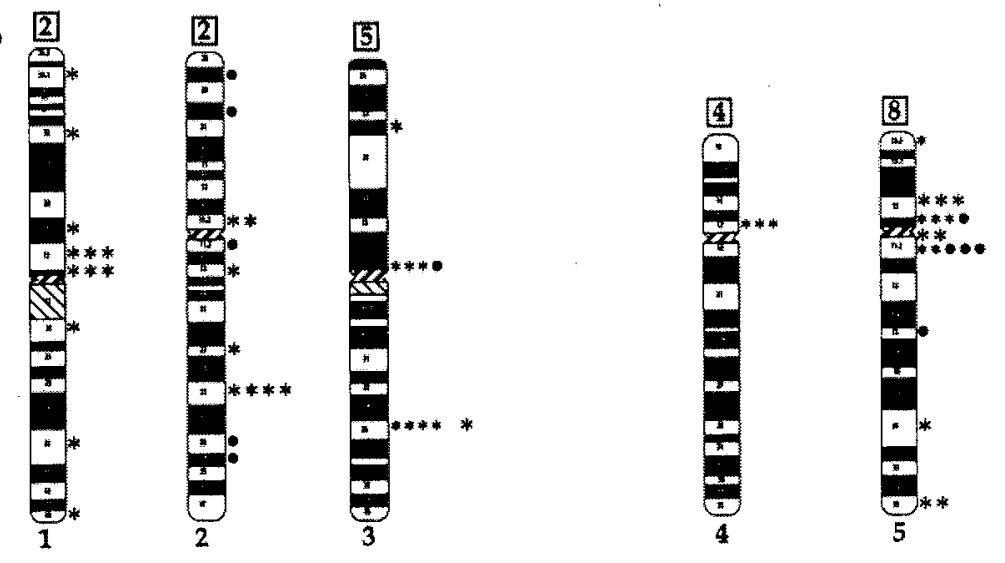

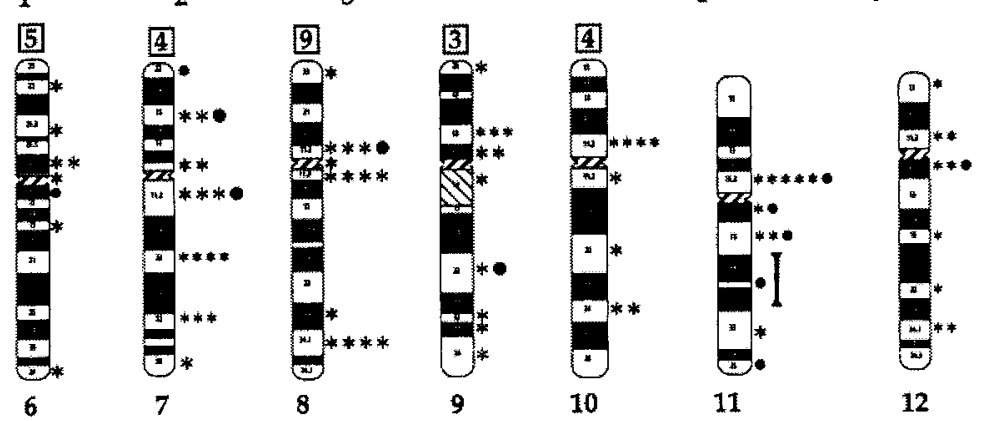

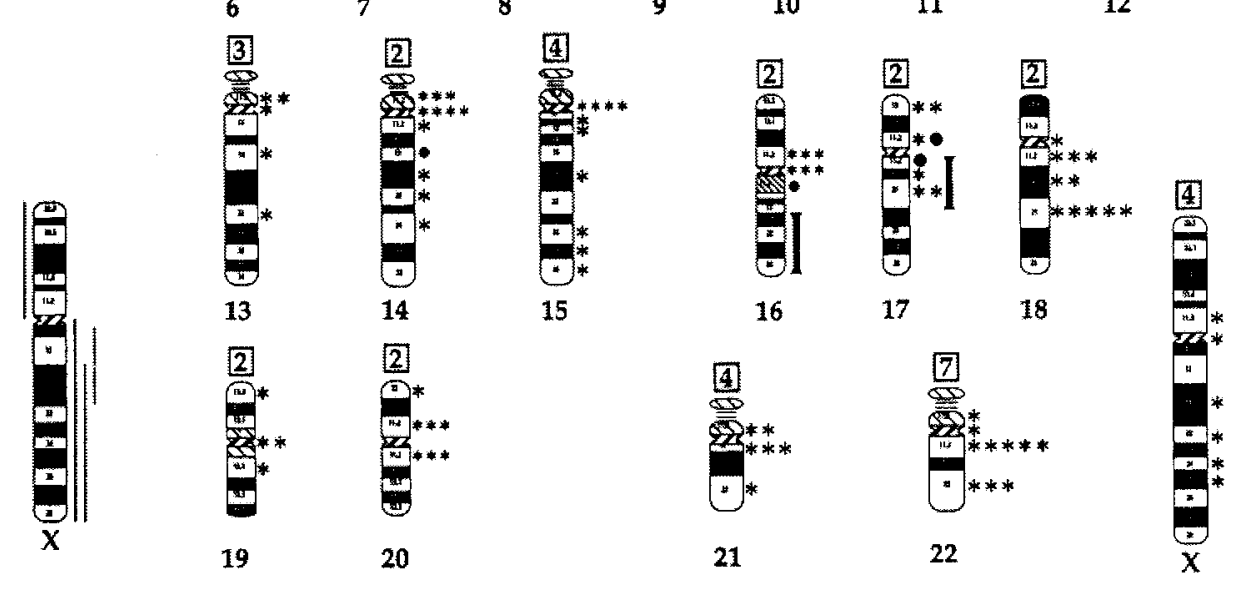


TABLE I. Combined G-Banded and SKY/Inverted DAPI Karyotypes of Eight Cervical Cancer Cell Lines

\begin{tabular}{|c|c|}
\hline Cell line & Karyotype \\
\hline Ca Ski & 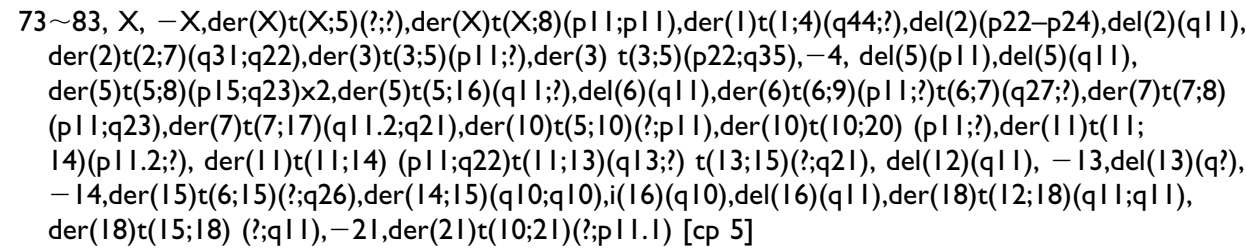 \\
\hline C-33A & 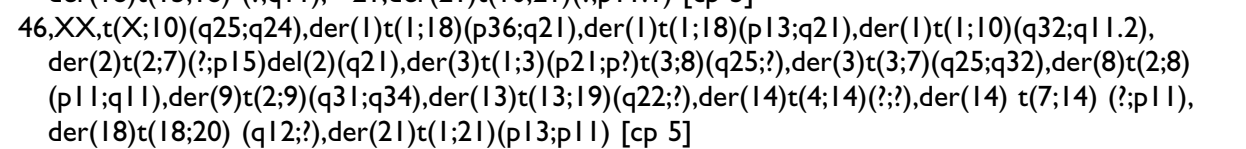 \\
\hline C-4I & 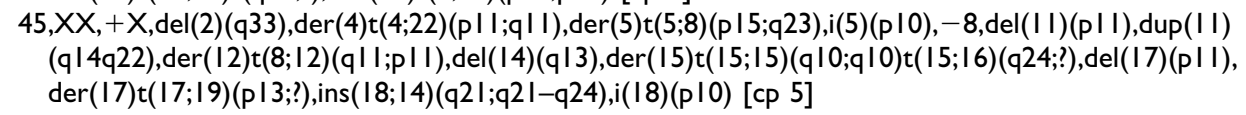 \\
\hline HT-3 & 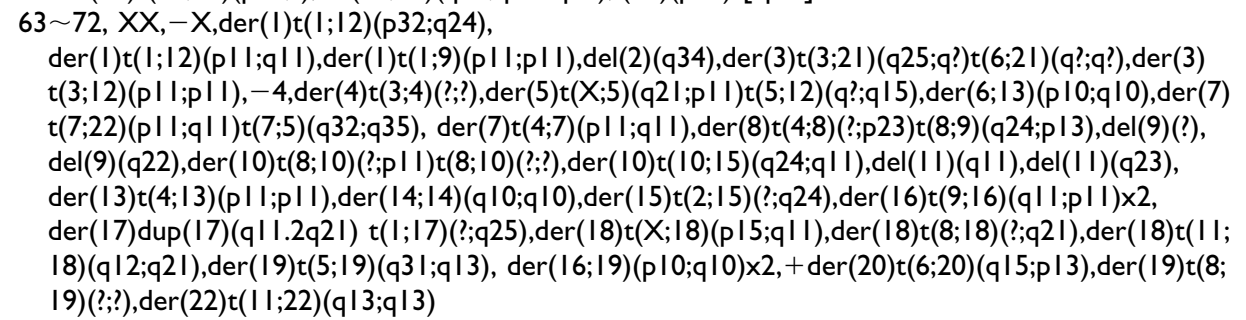 \\
\hline ME- 180 & 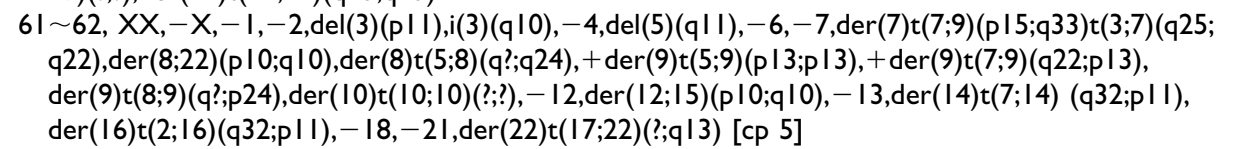 \\
\hline MS75I & 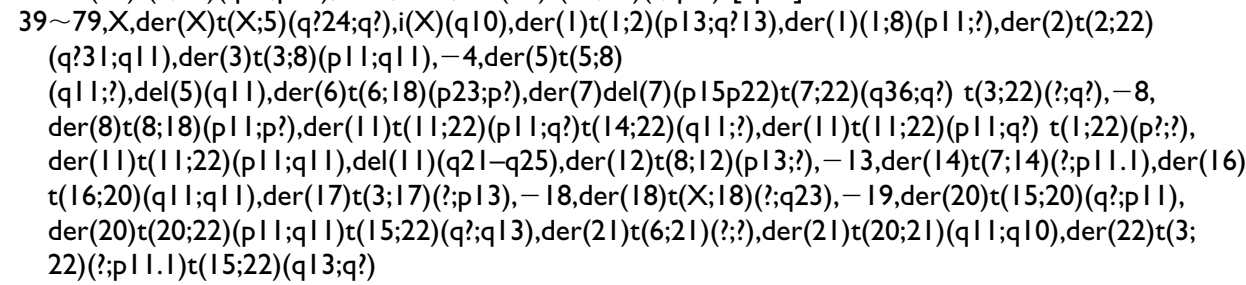 \\
\hline $\mathrm{SiHa}$ & 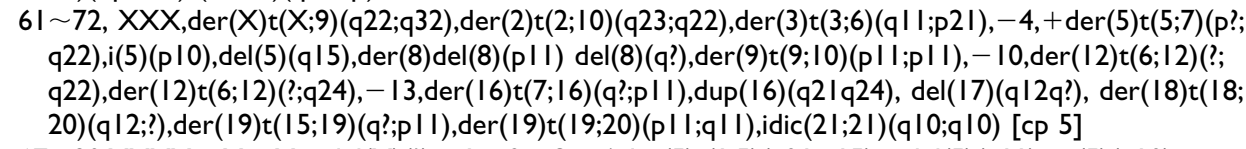 \\
\hline SW756 & 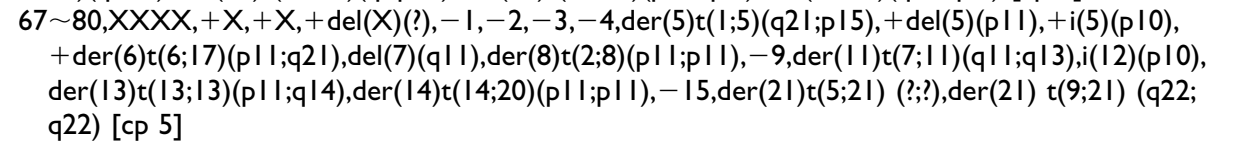 \\
\hline
\end{tabular}

High-level amplification was detected in eight chromosomal sites in seven cell lines at $3 \mathrm{q} 21$, 7p11.2, 8q23-q24, 10q21, 11q13, 16q23-q24, 20q11.2, and 20q13.1. Recurrent amplifications were noted in two sites at 7p11 (Ca Ski and MS751) and 11q13 (MS751 and HT-3). Non-recurrent amplifications were noted at 3q21 ( $\mathrm{SiHa}), 8 \mathrm{q} 23-\mathrm{q} 24$ (Ca Ski), 10q21 (ME-180), 16q23-q24 (SiHa), 20q11.2 (SW756), and 20q13.1 (C-33A).

\section{SKY Analysis}

A total of 116 translocations, 28 deletions, three duplications, and an insertion were identified by
SKY in the eight cell lines. Recurrent deletions affecting chromosomal bands were noted at $5 \mathrm{p} 11$ (Ca Ski, SW756), 5q11 (Ca Ski, MS751, SW756), and 11q23 (HT-3, MS751). Table 1 summarizes the karyotypes of the cell lines generated by SKY/ $\mathrm{G}$-banding. One reciprocal translocation was noted $[\mathrm{t}(\mathrm{X} ; 10)(\mathrm{q} 25 ; \mathrm{q} 24)$ in $\mathrm{C}-33 \mathrm{~A}]$ and a recurrent translocation [der(5)t(5;8) (p13;q23)] was noted in Ca Ski and C-4I. Robertsonian translocations involving $\operatorname{der}(14 ; 15)(q 10 ; q 10)$ in Ca Ski, der(14;14)(q10; $\mathrm{q} 10)$ in HT-3, and $\operatorname{der}(21 ; 21)(\mathrm{q} 10 ; \mathrm{q} 10)$ in $\mathrm{SiHa}$ were identified. Translocations involving whole chromosomal arms were identified in two cell lines: 
A
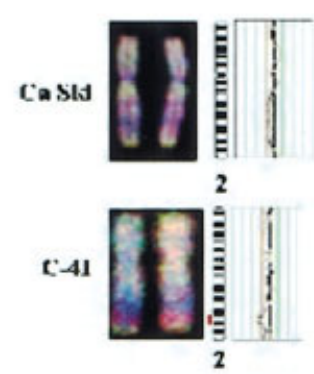

Ca Sk1
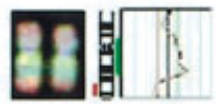

11
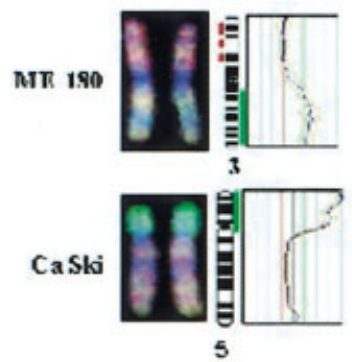

B
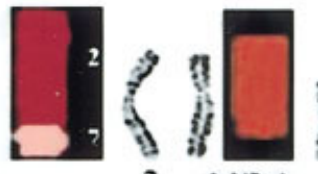

2 del $(2 p)$

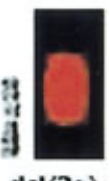

IIt
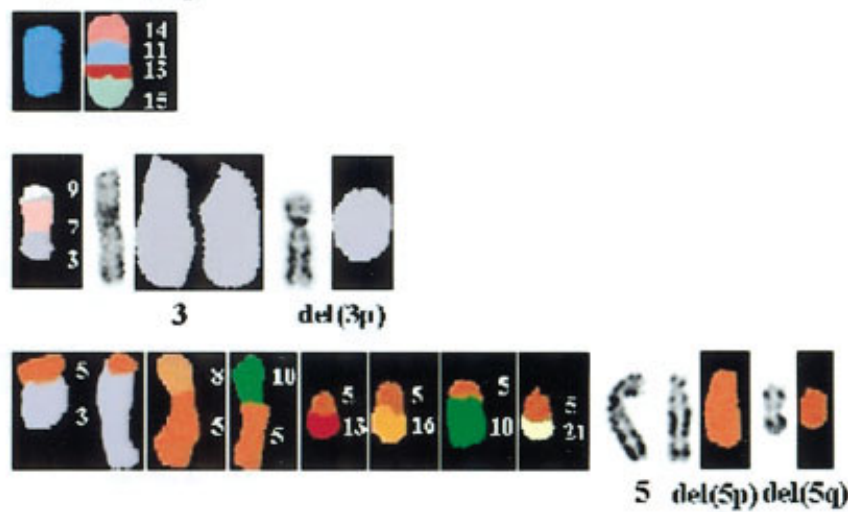

Figure 2. A: Partial CGH karyotypes for chromosome 2 (Ca Ski, C-4I), II (Ca Ski), 3 (ME-I80), and 5 (Ca Ski) (left) and corresponding ratio profiles (right) showing loss of $2 q, I I q$, and $3 p$ and gain of $3 q$. The vertical red and green bars on the right of the ideogram indicate the threshold values of 0.80 and 1.20 for loss and gain, respectively. B: Partial spectral karyotypes (classified images) of del(2q), del(2p), and der(2) in Ca Ski; del (2q) in C-4l; $\operatorname{der}(\mathrm{II})$ in Ca Ski; $\operatorname{del}(3 \mathrm{P})$ and $\operatorname{der}(3)$ in ME-I80; and $\operatorname{del}(5 \mathrm{p})$, del (5q), and $\operatorname{der}(5)$ in Ca Ski.

$\operatorname{der}(8 ; 22)(\mathrm{p} 10 ; \mathrm{q} 10)$ and $\operatorname{der}(12 ; 15)(\mathrm{p} 10 ; \mathrm{q} 10)$ in ME180 and $\operatorname{der}(6 ; 13)(\mathrm{p} 10 ; \mathrm{q} 10)$ and $\operatorname{der}(16 ; 19)(\mathrm{p} 10$; q10) in H'T-3. Six isochromosomes were noted: $\mathrm{i}(\mathrm{X})(\mathrm{q} 10)$ in MS751; $\mathrm{i}(3)(\mathrm{q} 10)$ in ME-180; $\mathrm{i}(5)(\mathrm{p} 10)$ in C-4I, SW756, and SiHa; i(12)(p10) in SW756; $\mathrm{i}(16)(\mathrm{q} 10)$ in $\mathrm{Ca}$ Ski; and $\mathrm{i}(18)(\mathrm{p} 10)$ in C-4I, of which $\mathrm{i}(5)(\mathrm{p} 10)$ is recurrent.

SKY/G-banding identified a total of 232 breakpoints in rearranged chromosomes, with another 79 assigned to chromosomes on the basis of the identification of chromosomal segments attached to or inserted into add or der chromosomes, but whose specific breakpoints could not be determined. Overall, recurring breaks (two or more) were noted in 51 sites. The breakpoint clusters (four or more) were seen at 2q31, 3p10, 3q25, 5p13, 5q11, 7q11.2, $7 \mathrm{q} 22,8 \mathrm{p} 11.2,8 \mathrm{q} 11.2,10 \mathrm{p} 11.2,11 \mathrm{p} 11.2,14 \mathrm{q} 10$, 15q10, 18q21, and 22q11.2 (Fig. 1B).

\section{Comparison of CGH and SKY Analysis}

There was a good concordance between the number of genomic imbalances identified by $\mathrm{CGH}$ and unbalanced structural aberrations identified by SKY. An example of the comparison is depicted in Figure 2, which displays a loss of 2q (Ca Ski and
C-4I) and 11q (Ca Ski) and loss and gain of 3p and 3q (ME-180) and 5p and 5q (Ca Ski).

An isochromosome for the short arm of chromosome $5[\mathrm{i}(5)(\mathrm{p} 10)]$ was noted by SKY in C-4I, SW756, and SiHa. The corresponding CGH profiles showed only a gain of chromosome arm $5 \mathrm{p}$ and no loss of $5 \mathrm{q}$. This may be attributable to the translocation of $5 \mathrm{q}$ chromosomal material to other chromosomes in the genome. The loss of $\mathrm{Xp}$ and gain of $\mathrm{Xq}$ in cell line MS751 and loss of 16p and gain of $16 \mathrm{q}$ in $\mathrm{Ca}$ Ski can be correlated with the presence of $\mathrm{i}(\mathrm{X})(\mathrm{q} 10)$ and $\mathrm{i}(16)(\mathrm{q} 10)$, respectively. SKY identified $\mathrm{i}(12)(\mathrm{p} 10)$ in SW756, but the corresponding CGH profiles were normal; this discrepancy may be ascribed to the low abundance of this clone in the tumor genome.

The partial or total loss of $2 \mathrm{q}$ was identified by $\mathrm{CGH}$ in all cell lines analyzed in the present study. The loss of $2 \mathrm{q}$ coincides with the presence of unbalanced structural rearrangements: $\operatorname{der}(2) \mathrm{t}(2$; 7)(?;p15) $\operatorname{del}(2)(\mathrm{q} 21)$ in $\mathrm{C} 33-\mathrm{A}, \operatorname{der}(2) \mathrm{t}(2 ; 22)(\mathrm{q} ? 31$; $\mathrm{q} 11)$ in $\mathrm{MS} 751, \operatorname{der}(2) \mathrm{t}(2 ; 10)(\mathrm{q} 23 ; \mathrm{q} 22)$ in $\mathrm{SiHa}$ and SW756, $\operatorname{del}(2)(\mathrm{q} 34)$ in C-4I, and $\operatorname{del}(2)(\mathrm{q} 33)$ and $\operatorname{der}(2) \mathrm{t}(2 ; 9)(\mathrm{q}$ ?31;p?) in HT-3. Both deletion $[\operatorname{del}(2)(q 11)]$ and unbalanced structural rearrange- 
ment $[\operatorname{der}(2) \mathrm{t}(2 ; 7)(\mathrm{q} 31 ; \mathrm{q} 22)]$ affecting $2 \mathrm{q}$ were noted in cell line Ca Ski. In cell line ME-180, CGH detected a loss of 2q, but the corresponding SKY analysis failed to show any aberration. This discrepancy may be ascribed to the limitation of sampling size by SKY.

In the majority of cases, the chromosomal amplification results from the unbalanced translocations material from one region to the other chromosomes in the genome except for SIHA, where it displayed the translocation, $\operatorname{der}(16) \mathrm{t}(7 ; 16)(\mathrm{q}$ ?; $\mathrm{p} 11)$, and duplication of the 16q21q24 region. However, the amplification at 10q21 in ME-180 and 11q13 in MS751 was visible only by $\mathrm{CGH}$.

\section{FISH Analysis}

We detected integration of HPV16 sequences in C-4I, Ca Ski, and ME-180 by FISH (Fig. 3). The HPV16 integration was noted at $18 \mathrm{p} 10$ on $\mathrm{i}(18)(\mathrm{p} 10)$ and at $18 \mathrm{p} 11$ on ins(18;14) (q21;q21q24) in C-4I, and on normal chromosome 17 at $17 \mathrm{p} 13$ in ME-180. In Ca Ski, HPV16 was integrated at 8q24 on $\operatorname{der}(\mathrm{X}) \mathrm{t}(\mathrm{X} ; 8)(\mathrm{p} 11 ; \mathrm{p} 11)$, at $2 \mathrm{p} 16$ on $\operatorname{del}(2)(\mathrm{p} 22-$ $\mathrm{p} 24)$, at $5 \mathrm{q} 21$ and $5 \mathrm{q} 23$ on $\operatorname{der}(5) \mathrm{t}(5 ; 8)(\mathrm{p} 13 ; \mathrm{q} 23)$, at $6 \mathrm{q}$ ? on $\operatorname{der}(6) \mathrm{t}(6 ; 9)(\mathrm{p} 11 ; ?)$, at $11 \mathrm{p} 11$ on $\operatorname{der}(11) \mathrm{t}(11 ; 14)(\mathrm{p} 11 ; \mathrm{q} 22)$ and $\operatorname{der}(11) \mathrm{t}(11 ; 14)(\mathrm{p} 11.2$; ?)t(11;13)(q13;?)t(13;15)(?;q21), at 18p11 on $\operatorname{der}(18)-$ $\mathrm{t}(12 ; 18)(\mathrm{q} 11 ; \mathrm{q} 11)$, at $15 \mathrm{q}$ ? on $\operatorname{der}(18) \mathrm{t}(15 ; 18)(? ; \mathrm{q} 11)$, and at 10 ? on $\operatorname{der}(21) \mathrm{t}(10 ; 21)(? ; \mathrm{p} 10)$ (Table 2 and Fig. 3). The HPV16 and $M Y C$ signals were detected as closely spaced signals on $\operatorname{der}(\mathrm{X}) \mathrm{t}(\mathrm{X}$; 8)(p11;p11)(p13;q23) in Ca Ski. On the basis of fluorescent signal intensity, we estimated the HPV16 copy number to be two to seven copies in Ca Ski and two to four copies in C-4I.

Because we identified recurrent gains at $3 \mathrm{q}$ and $8 \mathrm{q}$ by $\mathrm{CGH}$, we performed FISH analysis to estimate copy numbers in interphase nuclei and metaphase spreads through use of PIK3CA (3q26.3) and $M Y C(8 \mathrm{q} 24)$ as probes (Table 2). The distribution of copy number for $M Y C$ ranged from two to six copies, with more than five copies being noted in Ca Ski, ME-180, MS751, and SiHa. In the ME-180 cell line, we identified $\operatorname{der}(5) \mathrm{t}(5 ; 8)(\mathrm{p} 13 ; \mathrm{q} 23)$ by SKY, but FISH analysis identified this as a cryptic duplication of $M Y C$ on the $\operatorname{der}(5)$ chromosome (Fig. 3). This was consistent with the increased copy number identified by $\mathrm{CGH}$ at $8 \mathrm{q} 23-\mathrm{q} 24.1$. By use of PIK3CA (3q26.3) as a probe, FISH analysis revealed a copy number increase in C-4I (three to five copies), Ca Ski (two to four copies), and ME180 (two to three copies). These cell lines exhibited gain of chromosome arm 3q by CGH.

\section{DISCUSSION}

We report here a comprehensive molecular cytogenetic description of eight CC cell lines by G-banding, SKY, CGH, and FISH. CGH identified the most frequent chromosomal losses including 2q, 3p, 4q, 6q, 8p, 9p, 10p, 13q, and 18q; and gains including 3q, 5p, 5q, 8q, 9q, 11q, 14q, 16q, 17q, and 20q. The DNA copy number changes identified in this study are consistent with previously published CGH results for primary tumors (Heselmeyer et al., 1996; Dellas et al., 1999; Kirchhoff et al., 1999; Allen et al., 2000; Umayahara et al., 2002). Highlevel chromosomal amplifications at $3 \mathrm{q} 21,7 \mathrm{p} 11$, 8q23-q24, 10q21, 11q13, 16q23-q24, 20q11.2, and 20q13.1 were noted in seven of the eight cell lines.

An increased copy number for $3 \mathrm{q}$ was noted in four of the eight cell lines, and the common region mapped to $3 \mathrm{q} 26-\mathrm{q} 27$. The $3 \mathrm{q}$ gain was identified in a diverse group of tumors including head and neck, cervix, lung, and esophagus, and it has been shown to associate with a progression from highgrade CIN to invasive CG (Heselmeyer et al., 1996). Although previous studies have identified several candidate genes on $3 \mathrm{q} 26$ - q27, controversy still exists regarding the gene(s) that are the target of amplification in CG. The PIK3CA locus, which encodes a catalytic subunit of phosphatidylinositol 3-kinase, has been implicated as a candidate oncogene at 3q26 in carcinomas of the cervix, ovary, and head and neck (Shayesteh et al., 1999; Ma et al., 2000; Singh et al., 2001). We recently showed that the negative effect of TP53 induction on cell survival involves the transcriptional inhibition of PIK3CA that is independent of PTEN activity in squamous cell carcinomas (Singh et al., 2002). Another gene, $e I F-5 A 2$, a member of the eukaryotic initiation factor, which plays a role in translation initiation, has been implicated as a candidate oncogene in ovarian cancer (Guan et al., 2001). Gains of $5 p$ were noted in five of eight cell lines studied. This is suggestive of the presence of $\mathrm{i}(5)(\mathrm{p} 10)$ in the tumor genome and is consistent with previously published cytogenetic studies (Atkin, 1997). The telomerase reverse transcriptase (TERT) that maps to $5 \mathrm{p} 15$ has been shown to control the telomerase activity by an expression of its catalytic component. The TERT gene has been shown to be a putative oncogene and was amplified in several solid tumors, including cervical cancer (Greider, 1999; Zhang et al., 2002).

The loss of $2 \mathrm{q}$ was noted in $100 \%$ of the cell lines, and the common region of deletion was 


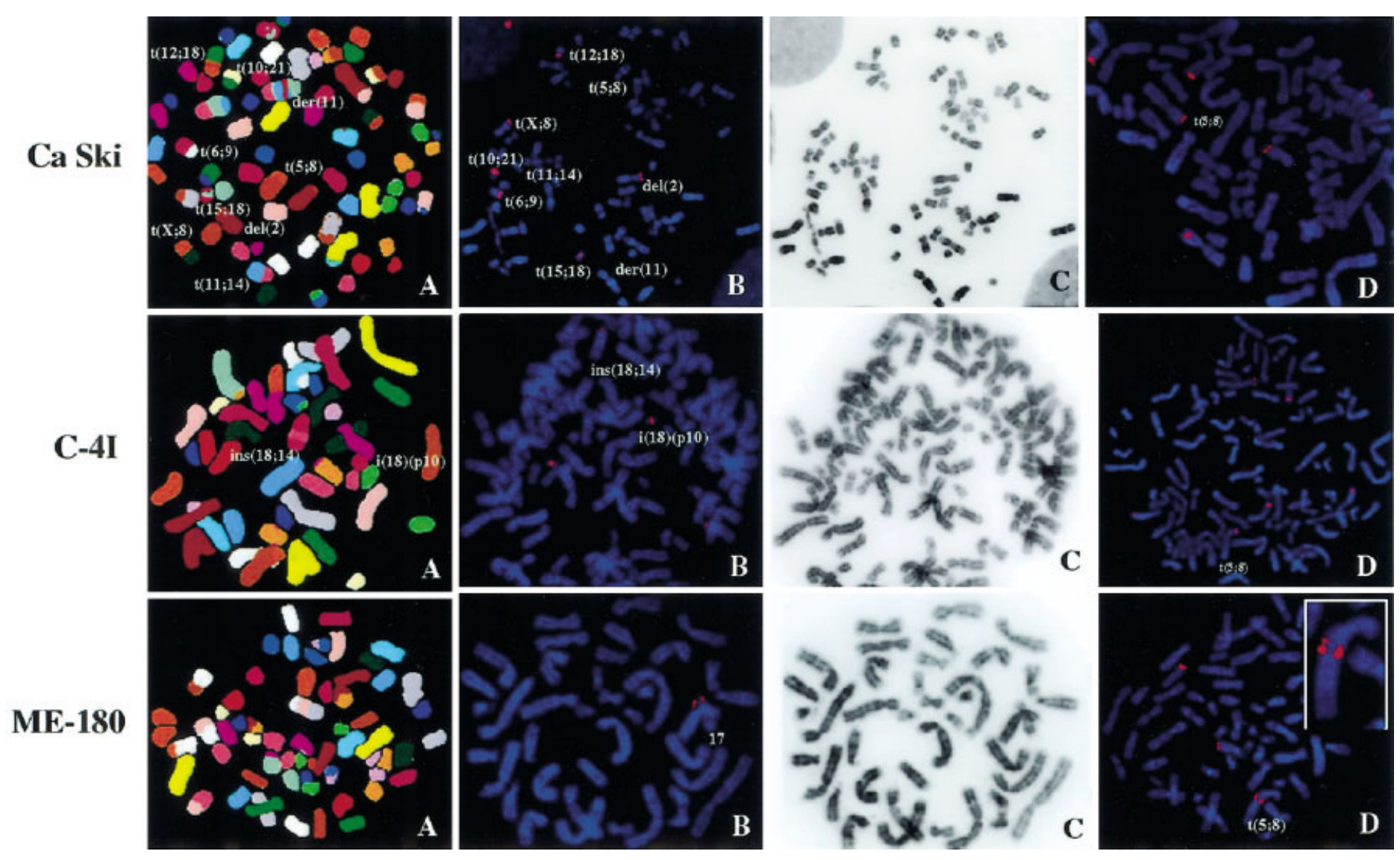

Figure 3. Metaphase spreads from Ca Ski, C-4l, and ME-180 hybridized with SKY painting probes, HPVI6, and MYC probes. For each image from left to right are spectral classified images (A), FISH images with HVPI6 integration sites (B), and corresponding DAPI (C) and MYC signals (D). The integrated HPVI6
sites are numbered in all metaphase spreads. Inset: Magnified image of duplicated MYC in the ME-180 cell line. 
TABLE 2. FISH Analysis of Eight Cervical Cancer Cell Lines

\begin{tabular}{|c|c|c|c|c|}
\hline \multirow[b]{2}{*}{ Cell line } & \multicolumn{2}{|c|}{ Number of copies } & \multirow[b]{2}{*}{ HPVI6 integration sites ${ }^{\mathrm{b}}$} & \multirow{2}{*}{$\begin{array}{l}\text { Previous } \\
\text { HPV status }\end{array}$} \\
\hline & PIK3CA & $M Y C^{\mathrm{a}}$ & & \\
\hline Ca Ski & $2-4(3 q 25-q 29)$ & $6(8 q 21.3-q 24.3)$ & 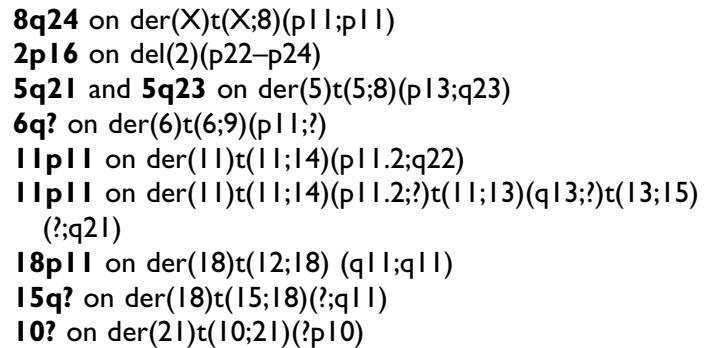 & HPVI6 \\
\hline C-33A & 2 & $2-4$ & None & Negative \\
\hline C-4I & $3-5(3 q 26-q 29)$ & $2-3$ & $\begin{array}{l}|8 p| 0 \text { on } \mathrm{i}(18)(\mathrm{p} \mid 0) \\
|8 \mathrm{p}| \mathbf{I} \text { on ins }(|8 ;| 4)(\mathrm{q} 2|; \mathrm{q} 2| \mathrm{q} 24)\end{array}$ & HPVI8 \\
\hline HT-3 & 2 & $2(8 q 23-q 24)$ & None & Negative \\
\hline ME-I80 & $2-3(3 q)$ & $4-6(8 q 23)$ & $17 p 13$ on 17 & HPV39 \\
\hline MS75 I & 2 & $3-6(8 q)$ & None & HPVI8 \\
\hline $\begin{array}{l}\text { SiHa } \\
\text { SW756 }\end{array}$ & $\begin{array}{c}2(3 q 2 I-q 23) \\
2\end{array}$ & $3-5(8 q 24)$ & None & $\begin{array}{l}\text { HPVI } 6 \\
\text { No information }\end{array}$ \\
\hline SW756 & 2 & $3-5(8 q)$ & None & No information \\
\hline
\end{tabular}

${ }^{\mathrm{a}} \mathrm{Gains}$ identified by $\mathrm{CGH}$ are presented in parentheses.

bHPVI6 integration breakpoints are in bold.

'Source: American Type Culture Collection (ATCC).

mapped to the 2q33-q36 region. SKY analysis also confirms the deletions as unbalanced structural rearrangements affecting the $2 \mathrm{q}$ region in seven of the eight cell lines. These data strongly suggest that this region harbors a tumor-suppressor gene(s). We recently identified two common regions of deletions at 2q34-q35 and 2q36.3-q37.1 by highresolution deletion mapping studies (data not shown). Other frequently deleted chromosomal regions were 1p, 3p, 4p, 4q, 6q, 7q, 8p, 11p, 11q, 13q, $17 \mathrm{p}, 17 \mathrm{q}, 18 \mathrm{q}, 19 \mathrm{p}$, and 19q. Some of these regions (e.g., 3p, 4q, 5p, 6p, and $11 \mathrm{p}$ ) were previously shown to be deleted by loss of heterozygosity studies (Atkin, 1997; Luft et al., 1999; Pulido et al., 2000; Chatterjee et al., 2001).

SKY analysis allowed the identification of novel breakpoints and recurrent translocations. Previous cytogenetic studies in primary tumors and cell lines identified several recurrent changes involving chromosomes 1, 3, 5, 11, 17, and the $\mathrm{X}$ chromosome (Atkin, 1997). The recurrent chromosomal rearrangements identified by SKY were translocation $\operatorname{der}(5) \mathrm{t}(5 ; 8)(\mathrm{p} 13 ; \mathrm{q} 23)$, i(5)(p10), and deletions affecting chromosomal bands 5p11, 5q11, and 11q23. SKY identified several breakpoint clusters at 2q31, 3p10, 3q25, 5p13, 5q11，7q11.2，7q22，8p11.2, 8q11.2, 10p11.2, 11p11.2, 14q10, 15q10, 18q21, and 22q11.2. Further, characterization of genes in the breakpoint clusters may provide clues for understanding the biology and clinical behavior of CC.
CC is shown to associate with HPV infection, particularly the high-risk types HPV16 and HPV18 (Canavan and Doshi, 2000). It has been established that the oncogenic HPV viral proteins E6 and E7 interact with and inactivate the tumor-suppressor proteins $\mathrm{p} 53$ and $\mathrm{pRb} 1$, thereby initiating a malignant transformation (zur Hausen, 2000). The HPV integration was found in a limited number of $\mathrm{CC}$ cell lines or primary tumors at normal or abnormal chromosomes. Recent molecular cytogenetic characterization of the HeLa cell line revealed HPV18 integration on normal chromosome 8 (8q24) and two derivative chromosomes involving the $8 \mathrm{q} 24$ band (Macville et al., 1999). In the present study, we noted HPV16 integration on normal chromosome 17 at $17 \mathrm{p} 13$ in the ME-180 cell line and two derivative chromosomes involving chromosome bands 18p10 and 18p11 in C-4I. In cell line Ca Ski, HPV integration was observed on one derivative chromosome involving the $8 \mathrm{q} 24$ band and another eight derivative chromosomes involving $2 \mathrm{p} 16$, $5 \mathrm{q} 21,5 \mathrm{q} 23,6 \mathrm{q}, 10,11 \mathrm{p} 11,15 \mathrm{q}$, and 18p11. This strongly suggests that the genomic reorganization is caused by HPV viral integration in cervical cancer. This is consistent with previously published correlation studies between the breakpoints in chromosomal rearrangements and HPV integration sites in cervical cancer (De Braekeleer et al., 1992).

In conclusion, we report here the precise and detailed characterization of eight frequently used 
CC cell lines by a combination of molecular cytogenetic methods, including CGH, SKY, and FISH. This comprehensive genetic characterization further augments experimental studies aimed at gene discovery.

\section{ACKNOWLEDGMENTS}

This work was supported by a grant from The Elain B. Lesser Foundation and The Herbert Irving Cancer Center, Columbia University (to V.V.V.S.M.). We are indebted to Drs. DeVilliers and Zur Hausen for kindly providing HPV16 plasmid.

\section{REFERENCES}

Allen DG, White DJ, Hutchins AM, Scurry JP, Tabrizi SN, Garland SM, Armes JE. 2000. Progressive genetic aberrations detected by comparative genomic hybridization in squamous cell cervical cancer. Br J Cancer 83:1659-1663.

Atkin NB. 1997. Cytogenetics of carcinoma of the cervix uteri: a review. Cancer Genet Cytogenet 95:33-39.

Brisson J, Morin C, Fortier M, Roy M, Bouchard C, Leclerc J, Christen A, Guimont C, Penault F, Meisels A. 1994. Risk factors for cervical intraepithelial neoplasia: differences between lowand high-grade lesions. Am J Epidemiol 140:700-710.

Canavan TP, Doshi NR. 2000. Cervical cancer. Am Fam Physician 61:1369-1376.

Chatterjee A, Pulido HA, Koul S, Beleño N, Perilla A, Posso H, Manusukhani M, Murty VVVS. 2001. Mapping candidate tumor suppressor sites at $6 \mathrm{p} 25$ and $6 \mathrm{p} 21.3$ in cervical carcinoma: occurrence of allelic deletions in precancerous lesions. Cancer Res 61:2119-2123.

De Braekeleer M, Sreekantaiah C, Haas O. 1992. Herpes simplex virus and human papillomavirus sites with chromosomal breakpoints in human cervical cancer. Cancer Genet Cytogenet 59:135137.

Dellas A, Torhorst J, Jiang F, Proffitt J, Schultheiss E, Holzgreve W, Sauter G, Mihatsch MJ, Moch H. 1999. Prognostic value of genomic alterations in invasive cervical squamous cell carcinoma of clinical stage IB detected by comparative genomic hybridization. Cancer Res 59: 3475-3479.

Greider CW. 1999. Telomerase activation: one step on the road to cancer? Trends Genet 15:109-112.

Guan XY, Sham JS, Tang TC, Fang Y, Huo KK, Yang JM. 2001. Isolation of a novel candidate oncogene within a frequently amplified region at 3q26 in ovarian cancer. Cancer Res 61:3806-3809.

Heselmeyer K, Schröck E, du Manoir S, Blegen H, Shah K, Steinbeck R, Auer G, Ried T. 1996. Gain of chromosome 3q defines the transition from severe dysplasia to invasive carcinoma of the uterine cervix. Proc Natl Acad Sci USA 93:479-484.

ISCN. 1995. An international system for human cytogenetic nomenclature. Mitelman F, editor. Basel: S. Karger.

Kallioniemi A, Kallioniemi OP, Sudar D, Rutovitz D, Gray JW, Waldman F, Pinkel D. 1992. Comparative genomic hybridization for molecular cytogenetic analysis of solid tumors. Science 258: $818-882$.

Kirchhoff M, Rose H, Petersen BL, Maahr J, Gerdes T, Lundsteen C, Bryndorf T, Kryger-Baggesen N, Christensen L, Engelholm SA, Philip J. 1999. Comparative genomic hybridization reveals a recurrent pattern of chromosomal aberrations in severe dysplasia/ carcinoma in situ of the cervix and in advanced-stage cervical carcinoma. Genes Chromosomes Cancer 24:144-150.

Luft F, Gebert J, Schneider A, Melsheimer P, Knebel Doeberitz M. 1999. Frequent allelic imbalance of tumor suppressor gene loci in cervical dysplasia. Int J Gynecol Pathol 18:374-380.

Ma YY, Wei SJ, Lin YC, Lung JC, Chang TC, Whang-Peng J, Liu JM, Yang DM, Yang WK, Shen CY. 2000. PIK3CA as an oncogene in cervical cancer. Oncogene 19:2739-2744.

Macville M, Schrock E, Padilla-Nash H, Keck C, Ghadimi B, Zimonjic D, Popescu N, Ried T. 1999. Comprehensive and definitive molecular cytogenetic characterization of HeLa cells by spectral karyotyping. Cancer Res 59:141-150.

Pulido HA, Fakruddin MJ, Chatterjee A, Esplin ED, Beleño N, Martínez G, Posso H, Evans GA, Murty VVVS. 2000. Identification of a $6 \mathrm{cM}$ minimal deletion at 11q23.1-23.2 and exclusion of PPP2R1B gene as a deletion target in cervical cancer. Cancer Res 60:6677-6682.

Rao PH, Cigudosa JC, Ning Y, Calasanz MJ, Iida S, Tagawa S, Michaeli J, Klein B, Dalla-Favera R, Jhanwar SC, Ried T, Chaganti RSK. 1998. Multicolor spectral karyotyping identifies newrecurring breakpoints and translocations in multiple myeloma. Blood 92:743-1748

Rao PH, Harris CP, Lu XY, Li XN, Mok SC, Lau CC. 2002. Multicolor spectral karyotyping of serous ovarian adenocarcinoma. Genes Chromosomes Cancer 33:123-132.

Schröck E, du Manoir S, Veldman T, Schoell B, Wienberg J, Ferguson-Smith MA, Ning Y, Ledbetter DH, Bar-Am I, Soenkensen D, Garini Y, Ried T. 1996. Multicolor spectral karyotyping of human chromosomes. Science 273:494-497.

Shayesteh L, Lu Y, Kuo WL, Baldocchi R, Godgrey T, Collins C, Pinkel D, Powell B, Mills GB, Gray JW. 1999. PIK3CA is implicated as an oncogene in ovarian cancer. Nat Genet 21:99-102.

Singh B, Gogineni SK, Sacks PG, Shaha AR, Shah JP, Stoffel A, Rao PH. 2001. Molecular cytogenetic characterization of head and neck squamous cell carcinoma and refinement of $3 q$ amplification. Cancer Res 61:4506-4513.

Singh B, Reddy PG, Goberdhan A, Walsh C, Dao S, Ngai I, Chou TC, O-charoenrat P, Levine AJ, Rao PH, Stoffel A. 2002. p53 regulates cell survival by inhibiting PIK3CA in squamous cell carcinomas. Genes Dev 16:984-993.

Speicher MR, Ballard SG, Ward DC. 1996. Karyotyping human chromosomes by combinatorial multi-fluor FISH. Nat Genet 12: $368-375$.

Umayahara K, Numa R, Suehiro Y, Sakata A, Nawata S, Ogata H, Suminami Y, Sakamoto M, Sasaki K, Kato H. 2002. Comparative genomic hybridization detects genetic alterations during early stages of cervical cancer progression. Genes Chromosomes Cancer 33:98-102.

Zhang A, Zheng C, Hou M, Lindvall C, Wallin K-L, Angstorm T, Yang X, Hellstrom A-C, Blennow E, Bjorkholm M, Zetterberg A, Gruber A, Xu D. 2002. Amplification of the telomerase reverse transcriptase ( $h T E R T)$ gene in cervical carcinomas. Genes Chromosomes Cancer 34:269-275.

zur Hausen H. 2000. Papillomaviruses causing cancer: evasion from host-cell control in early events in carcinogensis. J Natl Cancer Inst 92:690-698. 